\title{
Diagnóstico em Propriedades Leiteiras de Economia Familiar em Tabuleiro - MG
}

\author{
[Diagnosis in Family Owned Dairy Farms in Tabuleiro - Minas Gerais]
}

\section{"Artigo Científico/Scientific Article"}

\author{
Marco Aurélio Salgado Pires ${ }^{1}$, Gercílio Alves de Almeida Júnior ${ }^{2}$, Marcos Aurélio Lopes ${ }^{3 *}$
}

\author{
${ }^{1}$ Extensionista da EMATER - MG, Tabuleiro-MG, Brasil. \\ ${ }^{2}$ Departamento de Zootecnia, Universidade Federal do Espírito Santo, Alegre-ES, Brasil. \\ ${ }^{3}$ Departamento de Medicina Veterinária, Universidade Federal de Lavras, Lavras-MG, Brasil \\ *Autor para correspondência/Corresponding author: E-mail: malopes@dmv.ufla.br
}

\begin{abstract}
Resumo
Objetivou-se analisar o manejo das pastagens, nutricional, reprodutivo, sanitário, gestão e boas práticas na produção de leite e avaliar suas influências na produtividade dos rebanhos de 15 famílias do município de Tabuleiro - MG, selecionadas na Chamada Pública do Leite, no mês de abril de 2016. Foram aplicados formulários para levantar dados das propriedades, que contemplam os índices que ensejaram o estudo. Os dados obtidos foram inseridos em planilhas do software Sphinx ${ }^{\circledR}$ e agrupados de acordo com sua frequência e categoria. Os resultados mostraram que o manejo das pastagens apresenta deficiências que podem ser provocadas pela ausência de análise de solos e rotação de pastagens. A nutrição foi restritiva a bons desempenhos animais, havendo baixas produtividades de leite e elevada idade ao primeiro parto, com falhas frequentes na suplementação de volumosos, concentrados e sal mineral em parte ou em todas as propriedades. O manejo sanitário foi predominantemente curativo e precário na maioria absoluta das propriedades e as boas práticas preventivas de mastites também não eram devidamente adotadas. Não houve boa gestão financeira e zootécnica da atividade, o que limita as possibilidades de analisar os reais ganhos em produtividade e também o êxito na pecuária familiar.
\end{abstract}

Palavras-chave: atividade leiteira; caracterização da pecuária familiar; gestão na pecuária de leite.

\begin{abstract}
The objective of this study was to analyze pasture, nutrition, reproduction, sanitary and financial management, the good practices in milk production and evaluate their influence on the productivity of the herds from 15 families in the municipality of Tabuleiro - MG, selected in the Program Chamada Pública do Leite, in April 2016. Forms were used to collect farm data, which included the indices that led to the study. The data were inserted in spreadsheets using Sphinx ${ }^{\circledR}$ software and grouped according to their frequency and category. The results showed that pasture management presents deficiencies that are evidenced by the absence of soil analysis and pasture rotation. Nutrition is restrictive to good animal performance, with low milk productivity and high age at first calving, with frequent failures in supplementation of forage, concentrate, and mineral salt in part or all of the farms. Sanitary management was predominantly curative and precarious in the absolute majority of farms and good preventive practices of mastitis are also not properly adopted. There were no good financial and technical management of the activity, which limits the possibilities of evaluation of the real gains in productivity and also the success in family owned farms.
\end{abstract}

Keywords: dairy business; characterization of family farming; management of dairy cattle

\section{Introdução}

O Brasil ocupa posição de destaque na produção mundial de leite, sendo o quinto maior produtor de leite (FAO, 2013) e com produção no ano de 2015 estimada em 35 bilhões de litros (IBGE, 2016a). Contudo, no que diz respeito à produtividade, o país não apresenta o mesmo desempenho. Em 2011, a produtividade média foi de $1.600 \mathrm{~kg}$ de leite por vaca, enquanto o mundo, como um todo, alcançou, na média, a produtividade de $3.430 \mathrm{~kg}$ de leite por animal (BNDES, 2012). 
O Estado de Minas Gerais tem sido historicamente o maior produtor de leite no país e, em 2015, atingiu a produção de 9,1 bilhões de litros/ano (IBGE, 2016a). Embora sendo o maior produtor de leite do país, levantamento publicado em 2007, revelou que o Estado apresentava baixos índices de produtividade nos rebanhos. A produtividade média encontrada foi de 1.350 litros/vaca/ano, com aproximadamente $80 \%$ dos produtores produzindo menos de 200 litros de leite/dia, o que demonstrou a predominância de pequenos produtores, principalmente em agricultura familiar, nessa atividade (Marcatti Neto et al., 2007).

Outro estudo, realizado no ano de 2008, confirmou a baixa produtividade na região da Zona da Mata, onde está inserido o município de Tabuleiro, indicando a produção de diária de apenas 769.900 litros para um plantel de 486.500 vacas ordenhadas (Inaes, 2010). A produtividade média em Tabuleiro apresentou-se acima das produtividades regional e estadual, porém ainda incipiente. A produção anual foi de 3.240 .000 litros de leite, com 2.100 vacas ordenhadas, gerando a produtividade média de 1.543 litros/vaca/ano; com 190 agricultores, dos quais 180 eram familiares e responsáveis por $95 \%$ desta produção (EMATERMG, 2015).

Para se melhorar os índices de produtividade dos rebanhos, além de se investir no melhoramento genético do plantel, é necessário se adequar às boas práticas de manejo dos animais, o que engloba os manejos das pastagens, nutricional, reprodutivo e sanitário, além da gestão das propriedades. A adoção de boas práticas de manejo é necessária na atividade leiteira porque, além de assegurar melhoria na produtividade e qualidade do leite, garante eficiência na produção e traz benefícios socioeconômicos e ambientais para os agricultores.

O gerenciamento da propriedade rural é uma das ferramentas importantes e indispensáveis para se buscar o desenvolvimento sustentável da propriedade como um todo, independentemente do seu tamanho. O produtor enfrenta dificuldades específicas, tendo em vista que os sistemas de produção do setor rural, como a bovinocultura, são dotados de algumas especificidades que os distinguem dos demais sistemas de produção existentes, tais como o clima, a sazonalidade da produção, a perecibilidade dos produtos e a pouca qualificação da mão de obra (Lopes, 2015).

A EMATER - MG, em conjunto com o Ministério do Desenvolvimento Agrário, desenvolveu um contrato de prestação de serviço, denominado Chamada Pública do Leite, que tem como objetivo garantir assistência técnica e extensão rural aos produtores familiares e, assim, proporcionar melhorias na produção de leite de qualidade. Dentre os municípios participantes, está Tabuleiro e dentre as propriedades selecionadas, as avaliadas neste estudo.

Dessa forma, objetivou-se, com este estudo, analisar o manejo das pastagens, nutricional, reprodutivo, sanitário, gestão e de boas práticas na produção de leite, componentes de produção da bovinocultura leiteira, do município de Tabuleiro MG, e determinar as suas influências na produtividade do rebanho dos agricultores familiares, selecionados para serem atendidos na Chamada Pública do Leite.

\section{Material e Métodos}

O diagnóstico foi realizado em 15 propriedades de agricultores familiares, todos com mais de 10 anos na atividade leiteira, selecionados no município de Tabuleiro, na Zona da Mata de Minas Gerais, atendidos no programa da Chamada Pública do Leite. O município de Tabuleiro possui área geográfica de $211,38 \mathrm{~km}^{2}$ e apresentou população de 4.079 habitantes no censo demográfico de 2010 (IBGE, 2016b). A agropecuária é sua principal atividade econômica e a bovinocultura de leite exerce papel fundamental na vida dos agricultores familiares, constituindo a única fonte de renda de muitos deles (EMATERMG, 2015).

Foi aplicado o formulário de Diagnóstico da Unidade de Produção Familiar do Ministério do Desenvolvimento Agrário (MDA) (EMATER-GO, 2013), no mês de abril de 2016, com o propósito de analisar e identificar a influência dos aspectos relativos à produção, tendo como respondentes os agricultores familiares selecionados no programa. O formulário era composto por 66 questões, abrangendo os seguintes aspectos: caracterização do produtor, da propriedade e do rebanho, manejo nutricional e das pastagens, manejo reprodutivo e sanitário, gestão e boas práticas na produção de leite.

Nos manejos das pastagens e nutricional, foram levantadas respostas sobre a análise do solo, grau de degradação das pastagens, utilização de pastagem consorciada, tipo de suplementação, fornecimento de concentrado para vacas em lactação, fornecimento de concentrado para animais em recria, pastagens para vacas no pré- 
parto, suplementação volumosa do rebanho, divisão de pastagens, sistema de pastejo e tipo de cerca.

Quanto aos manejos reprodutivo e sanitário, foi questionado se os reprodutores eram selecionados no próprio plantel, se realizavam seleção das melhores matrizes e novilhas, tipo de procedimento reprodutivo adotado e se as raças utilizadas objetivavam elevar a produção do leite, idade do primeiro parto, intervalo de partos e período seco, se faziam vermifugação e controle de carrapatos dos animais.

$\mathrm{Na}$ gestão, o formulário levantou se os agricultores faziam anotação de receitas e despesas, controle leiteiro na propriedade, anotação de coberturas, partos e data de secagem dos animais e para qual empresa o leite era comercializado ou se beneficiavam o leite na propriedade. Também foram levantadas respostas sobre a média de leite na propriedade, quantidade de vacas em lactação, quantidade de vacas secas, total de animais no rebanho, produção média por vaca em lactação e produção média de vaca por rebanho.

Quanto às boas práticas de manejo, averiguou-se o tipo de ordenha, realização de teste para detecção de mastite, utilização de desinfetante para tetas pré e pós-ordenha, presença de tanque de resfriamento/expansão e sua utilização, conhecimento sobre os parâmetros de qualidade do leite como contagem de células somáticas (CCS), contagem bacteriana total (CTB) e unidades formadoras de colônias (UFC), número de ordenhas, presença de bezerro na ordenha $\mathrm{e}$ existência de pagamento por qualidade pelo laticínio.

Os dados obtidos foram inseridos em planilhas do software Sphinx ${ }^{\circledR} \quad$ (SPHINX BRASIL, 2011) e as respostas agrupadas de acordo com a suas frequências e categorias, segundo Bardin (2003). Os dados foram selecionados de acordo com sua categoria no formulário $\mathrm{e}$ conforme sua classe, para facilitar a velocidade de transcrição, interpretação e aplicação de ferramentas estatísticas.

\section{Resultados e Discussão}

Apenas quatro $(26,6 \%)$ dos 15 produtores realizavam análise de solos e o mesmo número declarou que havia algum grau de degradação nas suas pastagens (Tabela 1). A não realização anual de análise de solos é um indicativo da falta de profissionalismo na atividade, considerando que a pecuária de leite em propriedades familiares é normalmente muito dependente das pastagens e forrageiras de corte e, consequentemente, da fertilidade dos solos sob as plantas forrageiras. Uma das consequências da falta de manejo correto da fertilidade do solo é a degradação das pastagens e a diminuição dos índices de produtividade. Este processo é comumente observado naquelas regiões onde predominam as pastagens extensivas (Macedo, 2005), fato observado na maioria das propriedades avaliadas, onde apenas duas adotavam sistema de lotação rotacional em pastagens subdivididas. De acordo com Vilela (2001), cerca de 50\% dos 105 milhões de hectares de pastagens cultivadas existentes no Brasil estariam degradadas ou em degradação. As propriedades familiares são muito suscetíveis a esse problema em função da natureza predominantemente extensiva de sua produção.

Todos produtores forneciam capim picado como volumoso; contudo, observando a produtividade média dos rebanhos, de 7,37 litros/vaca/dia na lactação, pode-se deduzir que este volumoso não apresentava boa qualidade nutricional. A cana-de-açúcar (Saccharum officinarum) foi o segundo volumoso mais utilizado $(80 \%)$ pelos produtores, mas nenhum adicionava ureia quando da sua utilização. A silagem de milho (Zea mays) era utilizada em oito $(53,33 \%)$ propriedades e a de capim (Pennisetum purpureum), em uma (6,67\%) (Tabela 1).

Para se garantir maior produtividade necessita-se suplementar o rebanho com alimentos volumosos e com concentrados, em função dos requerimentos nutricionais de cada categoria animal e da composição química dos alimentos utilizados (EMBRAPA, 2002a). Nesse sentido, seis $(40 \%)$ das propriedades forneciam apenas sal comum na suplementação mineral do rebanho. Outras nove $(60 \%)$ forneciam suplemento mineral e/ou suplemento mineral proteico. A ração concentrada para as vacas em lactação era ofertada em $11(73,33 \%)$ das propriedades, mas nesse mesmo número de propriedades, as fêmeas em recria não recebiam nenhuma suplementação concentrada (Tabela 1).

Quanto ao manejo reprodutivo, $12(80 \%)$ dos produtores não selecionavam reprodutores dos seus próprios plantéis. No entanto, declararam selecionar as melhores fêmeas de reposição em 13 $(86,67 \%)$ das propriedades. A monta natural era adotada em dois terços das propriedades e somente cinco $(33,33 \%) \quad$ propriedades adotavam 
inseminação artificial comum ou em tempo fixo. Apenas seis $(40 \%)$ propriedades apresentavam idade ao primeiro parto entre 24 e 30 meses de idade; contudo, o intervalo de partos estava entre 12 e 14 meses em $11(73,33 \%)$ dos plantéis. O período seco das vacas situou-se predominantemente entre 60 e 90 dias e, na maioria (60\%) das propriedades, as novilhas e vacas no préparto não eram mantidas nas melhores pastagens, $o$ que pode ter contribuição negativa para o desempenho das vacas no pós-parto (Tabela 1).

Tabela 1. Caracterização dos manejos de pastagens, nutricional e reprodutivo nas 15 propriedades estudadas no município de Tabuleiro - MG, em abril de 2016.

\begin{tabular}{|c|c|c|c|}
\hline \multirow{2}{*}{ Questão } & \multirow{2}{*}{ Averiguação } & \multicolumn{2}{|c|}{ Quantidade } \\
\hline & & Total & $\%$ \\
\hline \multirow{2}{*}{ Realiza análise de solo? } & Sim & 4 & 26,67 \\
\hline & Não & 11 & 73,33 \\
\hline \multirow{2}{*}{$\begin{array}{l}\text { É observado algum grau de degradação de } \\
\text { pastagens? }\end{array}$} & Sim & 4 & 26,67 \\
\hline & Não & 11 & 73,33 \\
\hline Existe pastagem consorciada? & Não & 15 & 100,00 \\
\hline \multirow{2}{*}{ Utiliza pastejo rotacionado? } & Sim & 2 & 13,33 \\
\hline & Não & 13 & 86,67 \\
\hline \multirow{2}{*}{ Utiliza cerca eletrificada? } & Sim & 12 & 80,00 \\
\hline & Não & 3 & 20,00 \\
\hline \multirow{4}{*}{$\begin{array}{l}\text { Utiliza alguma suplementação volumosa para } \\
\text { o rebanho? }\end{array}$} & Silagem de milho & 8 & 53,33 \\
\hline & Silagem de capim & 1 & 6,67 \\
\hline & Cana-de-açúcar & 12 & 80,00 \\
\hline & Capim picado & 15 & 100,00 \\
\hline \multirow{4}{*}{$\begin{array}{l}\text { Qual tipo de suplementação mineral é } \\
\text { adotado? }\end{array}$} & Sal comum & 6 & 40,00 \\
\hline & Suplemento mineral & 6 & 40,00 \\
\hline & Suplemento mineral com ureia & 1 & 6,67 \\
\hline & Suplemento mineral proteico & 2 & 13,33 \\
\hline \multirow{2}{*}{ Fornece concentrado para vacas em lactação? } & Sim & 11 & 73,33 \\
\hline & Não & 4 & 26,67 \\
\hline \multirow{2}{*}{ Fornece concentrado para animais em recria? } & Sim & 4 & 26,67 \\
\hline & Não & 11 & 73,33 \\
\hline \multirow{2}{*}{$\begin{array}{l}\text { As vacas e novilhas prenhas são mantidas nos } \\
\text { melhores pastos? }\end{array}$} & Sim & 6 & 40,00 \\
\hline & Não & 9 & 60,00 \\
\hline \multirow{2}{*}{$\begin{array}{l}\text { Os reprodutores são selecionados no próprio } \\
\text { plantel? }\end{array}$} & Sim & 3 & 20,00 \\
\hline & Não & 12 & 80,00 \\
\hline \multirow{2}{*}{$\begin{array}{l}\text { O produtor realiza a seleção das melhores } \\
\text { matrizes e novilhas? }\end{array}$} & Sim & 13 & 86,67 \\
\hline & Não & 2 & 13,33 \\
\hline \multirow{3}{*}{$\begin{array}{l}\text { Qual tipo de procedimento reprodutivo } \\
\text { adotado na propriedade? }\end{array}$} & Monta natural & 10 & 66,67 \\
\hline & Inseminação artificial & 3 & 20,00 \\
\hline & Inseminação artificial em tempo fixo & 2 & 13,33 \\
\hline \multirow{3}{*}{ Qual a idade ao primeiro parto? } & 24 a 30 meses & 6 & 40,00 \\
\hline & 31 a 36 meses & 5 & 33,33 \\
\hline & Acima de 36 meses & 4 & 26,67 \\
\hline \multirow{2}{*}{ Qual o intervalo de partos? } & De 12 a 14 meses & 11 & 73,33 \\
\hline & Acima de 14 meses & 4 & 26,67 \\
\hline \multirow{3}{*}{ Intervalo da secagem da vaca e a parição } & 60 dias & 1 & 6,67 \\
\hline & De 60 a 90 & 11 & 73,33 \\
\hline & Acima de 90 & 1 & 6,67 \\
\hline
\end{tabular}

Para se obter boa produtividade nos plantéis leiteiros, a idade ao primeiro parto deve ser entre os 24 e 30 meses e as fêmeas gestantes precisam de cuidados especiais, sendo necessário que recebam alimentos de boa qualidade (EMBRAPA, 2002b). Segundo Sartori e Guardieiro (2010), a alimentação é essencial no desenvolvimento reprodutivo, uma vez que pode afetar direta ou indiretamente aspectos da fisiologia da fêmea bovina, sendo que técnicas de suplementação alimentar podem ser efetivas para garantir resultados favoráveis à fertilidade. 
Na Tabela 2 observa-se que, no manejo sanitário do rebanho, cerca de metade $(53,33 \%)$ das propriedades realizava controle sistemático de verminoses e infestação de carrapatos. A infestação por carrapatos; a carrapatose, é uma das principais doenças nos rebanhos leiteiros, principalmente naqueles com maior grau racial de holandês, causando grandes prejuízos e desconforto aos animais, com perdas consideráveis no desenvolvimento e na produção, além de transmitir outras doenças como a babesiose e a anaplasmose (EMBRAPA, 2002a).

As vacinações contra febre aftosa, brucelose e raiva eram realizadas em todas elas, o que pode estar relacionado com a exigência legal no caso da brucelose e febre aftosa, e da letalidade da raiva. Por outro lado, apenas um $(6,67 \%)$ entrevistado havia feito exame de brucelose e tuberculose; podendo, portanto, existir animais com estas doenças nos rebanhos. Nos rebanhos brasileiros existem doenças que representam grande preocupação e a tuberculose e a brucelose estão entre elas. Para o controle de brucelose e da tuberculose, o governo brasileiro mantém programas de controle do diagnóstico e de vacinação que o produtor tem que seguir à risca para garantir a saúde do rebanho. Ferreira e Miranda (2007) destacaram que os produtores deveriam direcionar seus esforços para programas preventivos, modificando a prática sanitária prevalente voltada para o aspecto curativo. Isso se confirmou nesta pesquisa, considerando que além da escassez de exames, a presença do veterinário acontecia apenas uma vez por ano em $80 \%$ das propriedades (Tabela 2).

Tabela 2. Caracterização do manejo sanitário nas 15 propriedades estudadas no município de Tabuleiro - MG, em abril de 2016.

\begin{tabular}{cccc}
\hline Questão & Averiguação & \multicolumn{2}{c}{ Quantidade } \\
& Total & \% \\
\hline É realizado o controle de verminose? & Sim & 8 & 53,33 \\
Quais vacinas são usualmente & Não & 7 & 46,67 \\
\cline { 2 - 4 } realizadas? & Febre Aftosa & 15 & 100,00 \\
& Brucelose & 15 & 100,00 \\
ná fez teste de brucelose no rebanho? & Raiva & 15 & 100,00 \\
\cline { 2 - 4 } É realizada alguma medida de controle & Sim & 1 & 6,67 \\
de carrapato? & Não & 14 & 93,33 \\
\cline { 2 - 4 } Frequência de visita de médico & Sim & 8 & 53,33 \\
veterinário a propriedade & Não & 1 & 46,70 \\
\hline
\end{tabular}

Na Tabela 3, observa-se que as propriedades avaliadas possuíam pequena quantidade de animais, em geral, com sete $(46,67 \%)$ delas tendo menos de 39 animais no rebanho. Dois terços dos produtores, possuíam menos de 11 vacas em lactação, sendo seus plantéis compostos por animais mestiços sem definição de grupo genético. Todas as propriedades adotavam produção em semiconfinamento, somente uma $(6,67 \%)$ ordenhava sem bezerro ao pé, mesmo sendo em ordenha mecânica, e cinco $(33,33 \%)$ faziam ordenha manual. $\mathrm{O}$ armazenamento do leite em tanques de expansão, ocorreu em $14(93,33 \%)$ das propriedades, sendo que em $10(66,67 \%)$ delas, era feito em tanques comunitários. A coleta do leite era realizada a cada dois dias em todas as propriedades. O perfil predominante foi de produções pequenas, abaixo de 89 litros por dia, para $60 \%$ dos produtores. Para este mesmo percentual de produtores, o volume comercializado diariamente foi inferior a 59 litros, evidenciando a utilização do leite para consumo interno e/ou produção de outros derivados. Somente uma $(6,67 \%)$ propriedade não comercializava o leite cru refrigerado. A comercialização pela maioria $(86,67 \%)$ dos agricultores era feita com laticínios, e dois $(13,33 \%)$ comercializavam com associação ou terceiros. Apenas dois $(13,33 \%)$ dos agricultores entrevistados faziam anotação de receitas e despesas e controle leiteiro. Portanto, na maioria dos casos não há como saber o custo de produção nem identificar, com segurança, as melhores vacas do rebanho. Anotação de datas de cobertura era feita por $10(66,67 \%)$ agricultores e nove $(60 \%)$ deles faziam registro de cobertura. Contudo, somente seis $(40 \%)$ proprietários registravam a data de secagem dos animais (Tabela 3 ). 
Tabela 3. Caracterização do rebanho e gestão da produção de leite nas 15 propriedades estudadas no município de Tabuleiro - MG, em abril de 2016.

\begin{tabular}{|c|c|c|c|}
\hline \multirow{2}{*}{ Questão } & \multirow{2}{*}{ Averiguação } & \multicolumn{2}{|c|}{ Quantidade } \\
\hline & & Total & $\%$ \\
\hline \multirow{2}{*}{ Total de animais } & Menos de 39 & 7 & 46,67 \\
\hline & Acima de 40 & 8 & 53,33 \\
\hline \multirow{2}{*}{ Quantidade de vacas em lactação } & Menos de 11 & 10 & 66,67 \\
\hline & Acima de 16 & 5 & 33,33 \\
\hline \multirow{2}{*}{ Quantidade de vacas secas } & Menos de 7 & 11 & 73,33 \\
\hline & Acima de 8 & 4 & 26,67 \\
\hline \multirow{4}{*}{ Raça bovina predominante } & Mestiça & 10 & 66,67 \\
\hline & $3 / 4 \mathrm{HxZ}$ & 2 & 13,33 \\
\hline & Girolanda & 2 & 13,33 \\
\hline & $1 / 2$ sangue & 1 & 6,67 \\
\hline Sistema de criação & Semiconfinado & 15 & 100,00 \\
\hline \multirow{2}{*}{ Tipo de leite produzido } & Leite cru refrigerado & 14 & 93,33 \\
\hline & Leite cru & 1 & 6,67 \\
\hline \multirow{2}{*}{ Ordenha } & Bezerro ao pé & 14 & 93,33 \\
\hline & Sem bezerro ao pé & 1 & 6,67 \\
\hline \multirow{2}{*}{ Tipo de ordenha } & Manual & 10 & 66,67 \\
\hline & Mecânica & 5 & 33,33 \\
\hline \multirow{3}{*}{ Armazena leite na propriedade? } & Sim & 4 & 26,67 \\
\hline & Não & 11 & 73,33 \\
\hline & Tanque de expansão & 4 & 26,67 \\
\hline \multirow[t]{2}{*}{ Caso "sim", como } & Outros & 1 & 6,67 \\
\hline & Tanque de expansão comunitário & 10 & 66,67 \\
\hline Quanto tempo fica na propriedade? & 2 dias & 15 & 100,00 \\
\hline \multirow{4}{*}{$\begin{array}{l}\text { Volume diário de leite produzido } \\
\text { atualmente }\end{array}$} & Menos de 89 & 9 & 60,00 \\
\hline & De 90 a 149 & 2 & 13,33 \\
\hline & De 150 a 200 & 4 & 26,67 \\
\hline & Menos de 59 & 9 & 60,00 \\
\hline \multirow[t]{3}{*}{ Volume diário de leite vendido atualmente } & De 60 a 119 & 2 & 13,33 \\
\hline & Acima de 150 & 4 & 26,67 \\
\hline & Laticínio & 13 & 86,67 \\
\hline \multirow[t]{2}{*}{ Como é feita a comercialização do leite? } & Associação & 1 & 6,67 \\
\hline & Terceiro & 1 & 6,67 \\
\hline \multirow{2}{*}{ Faz anotações de despesas e receitas? } & Sim & 2 & 13,33 \\
\hline & Não & 13 & 86,67 \\
\hline \multirow{2}{*}{ Faz controle leiteiro? } & Sim & 2 & 13,33 \\
\hline & Não & 13 & 86,67 \\
\hline \multirow{2}{*}{ Faz anotações de cobertura? } & Sim & 10 & 66,67 \\
\hline & Não & 5 & 33,33 \\
\hline \multirow{2}{*}{ Faz anotação de partos? } & Sim & 9 & 60,00 \\
\hline & Não & 6 & 40,00 \\
\hline \multirow{2}{*}{ Faz anotação de secagem de vacas? } & Sim & 6 & 40,00 \\
\hline & Não & 9 & 60,00 \\
\hline
\end{tabular}

O semiconfinamento de vacas leiteiras é pratica comum em propriedades familiares. Borges et al. (2015) afirmaram que, apesar dos diferentes sistemas de produção que caracterizam a atividade leiteira no Brasil, há predomínio do manejo semiintensivo de vacas mestiças, produtos do cruzamento entre bases genéticas de origens taurina e zebuína. Nos sistemas de manejo semi- intensivo, as fêmeas mestiças são mantidas em pastagens durante a estação chuvosa e suplementadas com volumoso durante a época de seca. Esses mesmos autores ainda destacaram que apesar de menos produtivas, as vacas mestiças Holandês x Zebu, que recebem suporte nutricional adequado, apresentam maior eficiência reprodutiva, menores incidências de doenças 
puerperais, taxas de descarte e taxas de mortalidade e maior longevidade no rebanho.

A ausência total ou parcial de controle zootécnico da produção e reprodução, bem como do controle de despesas e receitas, como observada no presente estudo, é comum entre produtores familiares. Ferreira e Miranda (2007) afirmaram que poucos produtores anotam o dia em que a vaca pariu, e sem esse registro é impossível calcular o intervalo de partos. Também, poucos produtores fazem controle leiteiro do rebanho, pelo menos uma vez por mês, e essa informação é imprescindível para um eficiente programa de melhoramento genético.

De acordo com Lopes et al. (2016), muitos proprietários rurais não administram suas propriedades com a eficiência requerida para serem competitivas no mercado e, assim sendo, o monitoramento dos índices zootécnicos e econômicos torna-se ferramenta essencial para a gestão da atividade leiteira. Ferrazza et al. (2015) também ressaltaram que a estimativa de índices de desempenho zootécnico e econômico, como instrumento de rotina, é uma ferramenta gerencial imprescindível para se verificar a viabilidade operacional e econômica do sistema de produção e fornecer com acurácia as informações necessárias para o planejamento e a tomada de decisão.

A utilização de índices nas propriedades produtoras de leite é fundamental para técnicos e proprietários porque eles estão associados à produção e consequentemente às possibilidades de viabilidade econômica da atividade. Portanto, o criterioso controle zootécnico e econômico pode auxiliar na determinação dos reais custos de produção, identificação de gargalos no sistema, maximização da produção e minimização dos custos (Lopes et al., 2009).

Conforme se observa na Tabela 4, a produção média por vaca em lactação ficou abaixo de 9 litros por dia e a produção média por vaca no rebanho, abaixo de 6 litros por dia, em 12 (80\%) das propriedades.

As baixas produções encontradas mostram que o manejo nutricional e a genética do rebanho são limitantes a ganhos de produtividade nas propriedades avaliadas. Lopes et al. (2016) encontraram a produção diária média de 11,6 litros por vaca em pequenas propriedades no Estado do Rio de Janeiro, enquanto Ferrazza et al. (2015) encontraram 10,9 litros diários por vaca em propriedades familiares nos Estados de Rio de Janeiro e Minas Gerais.
Apenas três produtores (20\%) faziam testes de detecção de mastite clínica diariamente; dois $(13,33 \%)$ realizavam o teste para detecção de mastite subclínica; e apenas um $(6,33 \%)$ fazia uso de solução desinfetante pré e pós ordenha, o que também pode estar influenciando na baixa produtividade dos plantéis (Tabela 4). O diagnóstico, prevenção e tratamento da mastite dependem da conscientização dos produtores. Como esta é uma doença que compromete a produção, afeta a composição e aumenta o risco de transmissão de doenças pelo leite, está diretamente ligada ao lucro do produtor (Pereira et al., 2012).

O impacto econômico dessa enfermidade é muito grande e evidencia a necessidade de monitoramento das formas clínica e subclínica da doença e adoção de medidas preventivas, para diminuir os prejuízos por ela ocasionados. É sabido que a mastite, além de reduzir a produção de leite, também altera sua composição, elevando a CCS (Spexoto et al., 2005). Segundo Pereira et al. (2012), a falta da desinfecção pode aumentar a incidência de mastites e reduzir em 20\% a produtividade da vaca. Contudo, as despesas com tratamento preventivo representaram, no máximo, $11,7 \%$ do impacto econômico, o que demonstra vantagens em investir nessa prática (Demeu et al., 2015). No que se refere aos fatores que influenciam no impacto econômico da mastite em rebanhos leiteiros, resultados de pesquisas são encontrados, tais como o efeito da produtividade diária de leite (Demeu et al., 2016), da escala de produção (Demeu et al., 2015), do descarte involuntário de matrizes (Demeu et al., 2011), do intervalo de partos (Lopes et al., 2009), da frequência média de mastite clínica (Lopes et al., 2012) e contagem de células somáticas (Lopes et al., 2011).

Dos entrevistados, sete $(46,67 \%)$ faziam uma ordenha por dia e os demais praticavam duas ordenhas diárias. De acordo com Ruas et al. (2006), a produtividade pode aumentar em pelo menos $20 \%$ ao se adotar a segunda ordenha. O diagnóstico apontou que todos os agricultores entrevistados conheciam os parâmetros de qualidade de leite: CCS, CBT e UFC. No entanto, somente três (20\%) dos entrevistados recebiam pagamento de leite por qualidade (Tabela 4).

De acordo com os resultados descritos na Tabela 4, observa-se que a ausência de pagamento do leite por qualidade é diretamente proporcional à ausência de boas práticas no manejo de ordenha nas propriedades avaliadas. Muito embora, todos os produtores tivessem conhecimento dos parâmetros 
de qualidade do leite, apenas a minoria adotava boas práticas, o que talvez esteja associado à ausência de estímulo financeiro pelo não pagamento de bonificação por qualidade, pelo laticínio comprador.

Tabela 4. Caracterização de índices relacionados à produção e das boas práticas na produção de leite nas 15 propriedades estudadas no município de Tabuleiro - MG, em abril de 2016.

\begin{tabular}{|c|c|c|c|}
\hline \multirow{2}{*}{ Questão } & \multirow{2}{*}{ Averiguação } & \multicolumn{2}{|c|}{ Quantidade } \\
\hline & & Total & $\%$ \\
\hline \multirow{7}{*}{ Produção média/vaca em lactação (litros/dia) } & Menos de 5 & 1 & 6,67 \\
\hline & De 5 a 6 & 2 & 13,33 \\
\hline & De 6 a 7 & 2 & 13,33 \\
\hline & De 7 a 8 & 4 & 26,67 \\
\hline & De 8 a 9 & 3 & 20,00 \\
\hline & Acima de 9 & 3 & 20,00 \\
\hline & Menos de 2 & 1 & 6,67 \\
\hline \multirow{5}{*}{ Produção média/vaca rebanho (litros/dia) } & De 2 a 3 & 3 & 20,00 \\
\hline & De 3 a 4 & 2 & 13,33 \\
\hline & De 4 a 5 & 3 & 20,00 \\
\hline & De 5 a 6 & 3 & 20,00 \\
\hline & Acima de 6 & 3 & 20,00 \\
\hline \multirow{2}{*}{ É realizado teste para identificação de mastite clínica? } & Sim & 3 & 20,00 \\
\hline & Não & 12 & 80,00 \\
\hline \multirow{2}{*}{ Faz teste de mastite subclínica? } & Sim & 2 & 13,33 \\
\hline & Não & 13 & 86,67 \\
\hline \multirow{2}{*}{ Utiliza solução desinfetante para tetas pré e pós ordenha? } & Sim & 1 & 6,67 \\
\hline & Não & 14 & 93,33 \\
\hline Conhece parâmetros de qualidade, CCS, CBT e UFC? & Sim & 15 & 100,00 \\
\hline \multirow{2}{*}{ Quantas ordenhas faz ao dia? } & Uma & 7 & 46,67 \\
\hline & Duas & 8 & 53,33 \\
\hline \multirow{2}{*}{ Recebe pagamento do laticínio por qualidade? } & Sim & 3 & 20,00 \\
\hline & Não & 12 & 80,00 \\
\hline
\end{tabular}

\section{Conclusão}

O manejo das pastagens nas propriedades leiteiras familiares do município de Tabuleiro apresenta deficiências que podem ser provocadas pela ausência de análise de solos e rotação de pastagens, e não permite que as mesmas apresentem melhores desempenhos técnicos e econômicos.

A nutrição é restritiva a bons desempenhos animais uma vez que aspectos básicos como fornecimento de sal mineral e correção da cana-deaçúcar com ureia não são seguidos em parte ou em todas as propriedades. As baixas produções médias de leite e predomínio de elevadas idades ao primeiro parto podem ter sido consequências da insuficiência qualitativa de volumosos ofertados em suplementação para as vacas em lactação e a ausência de suplementação concentrada para as fêmeas em recria pode estar afetando o seu desenvolvimento.

O manejo sanitário é predominantemente curativo e precário na maioria absoluta das propriedades e as boas práticas preventivas de mastites também não são devidamente adotadas.
A gestão financeira e zootécnica da atividade é negligenciada na maioria das propriedades, o que limita as possibilidades de analisar os reais ganhos em produtividade e também o êxito na pecuária familiar.

\section{Conflito de Interesse}

Os autores declaram não existir conflito de interesse.

\section{Comitê de Ética}

O diagnóstico foi realizado a partir de dados provenientes de propriedades assistidas pelo programa Chamada Pública do Leite da EMATERMG e MDA, não sujeito a avaliação de comitê de ética em utilização de animais, pois não houve experimentação animal.

Quanto à submissão a comitê de ética humano, também não houve necessidade, pois, os dados obtidos são anonimamente catalogados para elaboração de diagnósticos e perfis de propriedades e produtores de leite no Estado de Minas Gerais, com vistas à elaboração de políticas públicas de 
extensão rural, desenvolvimento sustentável e fomento pecuário.

\section{Agradecimentos}

Os autores agradecem à EMATER - MG, por ter possibilitado a realização desta pesquisa, e ao CNPq, pela concessão de bolsa de produtividade ao terceiro autor.

\section{Referências}

Banco Nacional de Desenvolvimento Econômico e Social - BNDES. Informativo Técnico Agris, n.4. Pecuária Leiteira. São Paulo: BNDES, 2012. Disponível em: < https://web.bndes.gov.br/bib/jspui/bitstream/14 08/2491/1/InformativoAGRIS_04_2012 _P.pdf $>$. Acesso em: 17 fev. 2017.

Bardin, L. Análise de conteúdos. Lisboa: Edições 70, 2003. 225p.

Borges, A.M.; Martins, T.M.M.; Nunes, P.P.; Ruas, J.R.M. Reprodução de vacas mestiças: potencialidade e desafios. Revista Brasileira de Reprodução Animal, 39(1), 155-163, 2015.

Demeu, F.A., Lopes, M.A., Costa, G.M., Rocha, M.C.M.B.; Santos, G.; Efeito da produtividade diária de leite no impacto economico da mastite em rebanhos leiteiros. Boletim de Indústria Animal, 73(1), 53-71, 2016.

Demeu, F.A., Lopes, M.A., Costa, G.M.; Rocha, M.C.M.B.; Santos, G.; Franco Neto, A. Influência do Descarte involuntário de matrizes no impacto economico da mastite em rebanhos leiteiros. Ciência e Agrotecnologia, 35(1), 195-202, 2011.

Demeu, F.A., Lopes, M.A., Rocha, M.C.M.B.; Costa, G.M., Santos, G.; Franco Neto, A. Influência da escala de produção no impacto econômico da mastite em rebanhos bovinos leiteiros. Revista Ceres, 62(2), 176-174, 2015.

Empresa Brasileira de Pesquisa Agropecuária EMBRAPA. Gado de leite: sistema de produção. Brasília: Embrapa, 2002a. Disponível em: <https://sistemasdeproducao. cnptia.embrapa.br/FontesHTML/Leite/LeiteCe rrado/importancia.html>. Acesso em: $04 \mathrm{dez}$. 2015.

Empresa Brasileira de Pesquisa Agropecuária EMBRAPA. Produção de leite no semi-árido do Brasil. Petrolina: Embrapa Semi-Árido, 2002b. Disponível em: <https://sistemasdeproducao.cnptia.embrapa.br /FontesHTML/Leite/LeiteSemiArido/manejo/ parasitos.html>. Acesso em: 30 mai. 2016.
Empresa de Assistência Técnica e Extensão Rural do Estado de Goiás - EMATER - GO. Diagnóstico da Unidade de Produção Familiar - UPF. Goiânia: EMATER-GO, 2013. Disponível em: < http://www.emater.go.gov.br/intra/wpcontent/uploads/downloads /2013/07/Chamada-SustentabilidadeDiagonstico-DA-UPF.pdf >. Acesso em: $12 \mathrm{dez}$. 2015.

Empresa de Assistência Técnica e Extensão Rural do Estado de Minas Gerais - EMATER - MG. Sistema de Safra Pecuária 2015. Belo Horizonte: EMATER-MG, 2015. Disponível em:

<http://www.emater.mg.gov.br/portal.cgi?flag web=intranet_tpl_sistema_pecuaria $>$. Acesso em: 12 dez. 2015.

Ferrazza, R.A.; Lopes, M.A.; Bruhn, F.R.P.; Moraes, F. Índices de desempenho zootécnico e econômico de sistemas de produção de leite com diferentes tipos de mão de obra. Ciência Animal Brasileira, 16(2), 193-204, 2015.

Ferreira, A.M.; Miranda, J.E.C. Medidas de eficiência da atividade leiteira: índices zootécnicos para rebanhos leiteiros. Comunicado Técnico, n.54, p.1-8. Juiz de Fora: Embrapa, 2007. Disponível em: <http://www.cnpgl.embrapa.br/totem/conteudo /Outros_

assuntos/Comunicado_Tecnico/COT54_Medid as_de_eficiencia_da_ativ_leiteira_indices_zoot ecnicos.pdf >. Acesso em: 25 mai. 2016.

Food and Agriculture Organization - FAO. FAO Statistical Yearbook 2013: World Food and Agriculture. Rome: FAO, 2013. Disponível em: $\quad<$ http://www.fao.org/ docrep/018/i3107e/i3107e00.htm>. Acesso em: 10 jul. 2017.

Instituto Antonio Ernesto de Salvo - INAES. Perfil do produtor de leite da Zona da Mata e Campo das Vertentes de Minas. Belo Horizonte: Sistema FAEMG, 2010. Disponível em:

<http://www.sistemafaemg.org.br/Conteudo. asp $x$ ? Code $=1404 \&$ Portal $=4 \&$ ParentCode $=$ 1402\&ParentPath $=$ None\&

ContentVersion=C $\geq$. Acesso em: 17 ago. 2016.

Instituto Brasileiro de Geografia e Estatística IBGE. Produção da Pecuária Municipal 2015. Rio de Janeiro: IBGE, 2016a. Disponível em: <http://biblioteca.ibge.gov.br/ 
visualizacao/periodicos/84/ppm_2015_v43_br. pdf>. Acesso em: 10 jul. 2017.

Instituto Brasileiro de Geografia e Estatística IBGE. Cidades. Rio de Janeiro: IBGE, 2016b. Disponível em: $<$ https://cidades.ibge.gov.br/v4/brasil/mg/tabul eiro/ panorama $\geq$. Acesso em: 17 jul. 2017.

Lopes, M.A. Gestão na bovinocultura de leite. Lavras: Editora UFLA, 2015. 97p.

Lopes, M.A; Demeu, F.A; Rocha, C.M.B.M.; Costa, G.M.; Franco Neto, A.; Santos, G. Avaliação do impacto econômico da mastite em rebanhos leiteiros. Arquivos do Instituto Biológico, 79(4), 477-483, 2012.

Lopes, M.A; Demeu, F.A; Costa, G.M.; Rocha, C.M.B.M.; Abreu, L.R.; Santos, G.; Franco Neto, A. Influência da contagem de células somáticas sobre o impacto econômico da mastite em rebanhos bovinos leiteiros. Arquivos do Instituto Biológico, 78(4), 493499, 2011.

Lopes, M.A.; Dias, A.S.; Carvalho, F.M.; Lima, A.L.R.; Cardoso, M.G.; Carmo, E.A. Resultados econômicos de sistemas de produção de leite com diferentes níveis tecnológicos na região de Lavras, MG nos anos 2004 e 2005. Ciência e Agrotecnologia, 33(1), 252-260, 2009.

Lopes, M.A.; Moraes, F.; Carvalho, F.M.; Peres, A.A.C.; Bruhn, R.P.; Reis, E.M.B. Effect of technical indexes on cost-effectiveness in dairy farms participating in the "Balde Cheio" program at different stages of production. Semina: Ciências Agrárias, 37(6), 4235-4242, 2016.

Macedo, M.C.M. Degradação de pastagens: conceitos, alternativas e métodos de recuperação. Informe Agropecuário, 26(226), 36-43, 2005.

Marcatti Neto, A.; Gonçalves Filho, A.F.; Godoy, M.; Amaral, R.; Azevedo, N.A.; Silva, J.B. Diagnóstico da pecuária leiteira do município de Barroso. Belo Horizonte: EPAMIG, 2007. 24p.

Pereira, D.A.; Machado, G.M.; Teodoro, V.A.M. Boas práticas de ordenha. Belo Horizonte: EPAMIG, 2012. 28p.

Ruas, J.R.M.; Brandão, F.Z.; Silva Filho, J.M.; Borges, A.M.; Carvalho, B.C.; Menezes, A.C.; Amaral, R.; Marcatti Neto, A. Influência da frequência de ordenhas diárias sobre a eficiência produtiva de vacas mestiças Holandês-Zebu e o desempenho de seus bezerros. Revista Brasileira de Zootecnia, 35(2), 428-434. 2006.

Sartori, R.; Guardieiro, M.M. Fatores nutricionais associados à reprodução da fêmea bovina. Revista Brasileira de Zootecnia, 39(suplemento), 422-432. 2010.

Spexoto, A.A.; Oliveira, C.A.; Olival, A.A. Aplicação do Sistema de análise de perigos e pontos críticos de controle em propriedades leiteira tipo A. Ciência Rural, 35(6), 14241430. 2005.

Sphinx Brasil. Manual de uso do software Sphinx rápido. $2^{\mathrm{a}}$. ed. Canoas: Sphinx Brasil, 2011.47p.

Vilela, D. Apresentação. In: Carvalho, M.M.; Alvim, M.J.; Carneiro, J.C. (Ed.). Sistemas agroflorestais pecuários: opções de sustentabilidade para áreas tropicais e subtropicais. Juiz de Fora: Embrapa Gado de Leite, 2001. p.3-4. 